\title{
ENGAGE ANTIRACISM, DIVERSITY, EQUITY, AND INCLUSION: APPLICATIONS TO SCHOOL SETTINGS
}

JODEE KELLER and GIESELA GRUMBACH

\section{CASE SCENARIO 4.1: The Case of Unexamined Bias}

Ms. Kate, an elementary school social worker, was observed by her student intern Rosalie as she taught a lesson about body safety to a second-grade class. Ms. Kate had been a social worker for 10 years and was at a school with an increasingly diverse enrollment. As the lesson progressed, students became eager to participate and answer questions.

Ms. Kate interspersed several questions throughout her lesson. The students were bursting with excitement as they anxiously awaited their turn to be called on. Many of them signaled their desire to answer questions by waving their hands up and down frenetically. Ms. Kate called on many of the students at least once yet ignored one little girl, Maye, whose chance to participate never seemed to come. Maye was a pretty little girl with micro-braids, and she was of African American descent. Rosalie began to wonder why Ms. Kate would not call on this little girl, who was following classroom rules by raising her hand, not speaking out of turn, and demonstrating a desire to participate. Rosalie brought this up in her field seminar class and was timid to approach the topic in supervision with Ms. Kate.

\section{REFLECTION QUESTIONS}

1. What is troubling about this scenario?

2. Is Rosalie being overly sensitive?

3. Do Ms. Kate's actions demonstrate undiscovered bias in this scenario?

4. How might Rosalie raise her concerns in supervision?

5. Maye was the only student in the classroom with dark skin; several other children of mixed heritage with much lighter skin were called on but not Maye-was this a case of colorism?

6. Could Ms. Kate's failure to call on Maye be considered a microaggression (microinsult)? 
As social workers, we have a responsibility to engage in disciplined practices such as self-reflection. Our goal should always be to first do no harm. The continual practice of examining our beliefs, values, and biases is critical to engaging in best practice. Ms. Kate failed to acknowledge Maye, an action that should be examined by the worker. Sue and colleagues (2015) define racial microaggressions as those insidious, harmful, forms of racism (racist slights) that are commonplace occurrences (intentional or unintentional). As Sue and colleagues explain, microinsults can be nonverbal as well. In this instance, the social worker who failed to acknowledge the student of color in the classroom, delivered a racial insult or microaggression whether intended or not. The student was a well-behaved, well-dressed little girl whose enthusiastic efforts were ignored.

Microaggressions influence the learning environment and the learner's experiences. Researchers have documented the effects of microaggressions on people who experience them (i.e., microaggressions whether intended or not). Sue (2010) writes about the ways in which microaggressions compromise the recipient's self-confidence and imbue feelings of worthlessness. The educational environment must be a safe place where children are able to learn in a space free from indignities such as racialized microaggressions. School social workers should be reminded of the call to action and "advocate for an examination of microaggressions in the larger context of social structures in which they occur" (Nakaoka \& Ortiz, 2018, p. 73). All adults in the educational system should promote the rights of all students allowing them the freedom to develop self-esteem and have their self-worth mirrored to them in the healthiest possible way. As school social workers, we should treat all children with unconditional positive regard.

\section{EDUCATIONAL POLICY AND ACCREDITATION STANDARDS/ LEARNING OBJECTIVES}

\section{Competency 2: Engage in Antiracism, Diversity, Equity, and Inclusion in Practice}

Social workers are called to understand how racism and oppression permeate our society, shape identity formation and human experience, and affect practice at individual, family, group, organization, community, and policy levels. Social workers are trained to understand how context shapes one's life experiences. The Council on Social Work Education (CSWE, 2021) explains that diversity is understood from an intersectional point of view based on the multidimensions of one's identity.

As competent social work practitioners, we are called to understand how multiple intersecting oppressions impact the lives of the clients we serve. Intersecting forms of oppression include poverty, marginalization, and alienation. Juxtaposed to these forms of oppression are privileges of power and acclaim. Social workers additionally recognize the enduring impact of White privilege, growing out of White supremacy, and engage in self-reflection to enact antiracist practices that demonstrate self-awareness, a strong knowledge base, and a growing competence. Competent social workers understand mechanisms of oppression and discrimination and work to ameliorate their effects on the promotion of social justice. The CSWE (2021) also acknowledges the impact of culture on one's ability to either experience privilege and power or margination and oppression. Further social workers must understand how to function in a competent manner across all levels (i.e., micro, mezzo, and macro). 
By the end of the chapter, you will be able to (based on CSWE EPAS):

- Implement antiracist practice with systems of all sizes and utilize a decolonial stance in incorporating theories and voices of marginalized populations.

- Present yourself as a learner and recognize students and families as experts of their own experiences.

- Become aware of your own personal biases and utilize critical self-reflection, self-awareness, and self-regulation to manage the effects of biases, personal values, power, and privilege when working with diverse populations.

Additionally, by the end of the chapter you will be able to:

- Discuss key concepts of diversity and inclusion.

- Understand the continuum of cultural competence, diversity, humility, and responsiveness.

- Understand the role of the school social worker in promoting diversity and inclusion.

- Consider the role of the school social worker in challenging forms of oppression.

\section{INTRODUCTION}

This chapter reviews important concepts of diversity, inclusion, racial power dynamics, and racial justice. The social work profession is grounded in a social justice ethic that honors the worth of all individuals. Social, economic, and racial justice are salient to the social work profession.

In the literature, scholars give discourse about the lack of structures in place to counter predominant power relations (Stone, 2017). Furthermore, Stone (2017) argues that the literature does not attend to professional practices within schools, institutional routines, or professional practices "that ultimately maintain an inequitable status quo" (p. 1238).

Stone argues for a racial justice and equity framework for school social work. Specifically, Stone (2017) suggests that we call attention to "(a) school institutional and organizational structure and (b) school social work practice routines to center issues of racial justice and equity in relation to the school social work profession" (p. 1238). Other bodies of literature are beginning to examine structural competency to give attention to socially structured and racialized power relations. Many of these rich discussions are missing from school social work discourse although school social work scholarship addresses racially based educational disparities (Stone, 2017). Stone suggests that school structure and social work practice routines are important considerations for enacting racial justice and equity.

\section{SCHOOL STRUCTURE AND STUDENTS OF COLOR}

The school system has not been spared from the tumultuous racial oppression and separatist policies of the past. In fact, the United States was founded on fundamental injustices. Every immigrant group entering the United States has suffered some form of inhumane treatment. Nonetheless, people of color have an enduring experience of oppression. American Indians for instance, suffered deeply from the ethnocide/boarding school experiences and other forms of displacement from their land. African Americans/ 
Blacks continue to endure racial indignities and sustained brutality longer than any other ethnic group (Feagin, 2004). Japanese Americans experienced internment camps during the Second World War. Notably, Teasley and Homer (2020) write about the plight of Mexicans related to school segregation, "Although little is shared on . . . Hispanics and school segregation, it is important to note that a 1947 federal . . . case, Mendez et al v. Westminster, held that segregated schools for Mexicans in Orange County, California, were unconstitutional and unlawful" (p. 2). Dating back to 1930, in certain areas/towns in Texas with large size Mexican populations, Mexican-only schools were created. The rationale was that Mexicans needed their own schools due to significant language issues. While the segregation of Black students was de jure, Wilson (2003) argues that the segregation of Mexican students was not.

These brief historical facts are an important reminder since these deeply embedded values and policies have impacted the school setting. Although we are living in a post-Brown v. Board of Education era, Brown was never fully realized. Instead, some scholars contend that we are "still subjected to Plessy-like (i.e., separate and 'unequal') racial ideologies and contemporary experiences" (Smith, 2012, p. 37). McCardle and Bliss (2019) assert that Brown v. Board of Education (347 U.S. 483), argued by Thurgood Marshall, has a lingering effect in the United States although it was passed six decades ago. Brown v. Board of Education was the landmark case that ruled de jure segregation of schools unconstitutional (see Figures 4.1 and 4.2). De jure refers to legal segregation and the refusal to adhere to this constitutional ruling led to de facto segregation. To avoid desegregation, many White people moved to suburban areas away from Black people to prevent their children from attending integrated

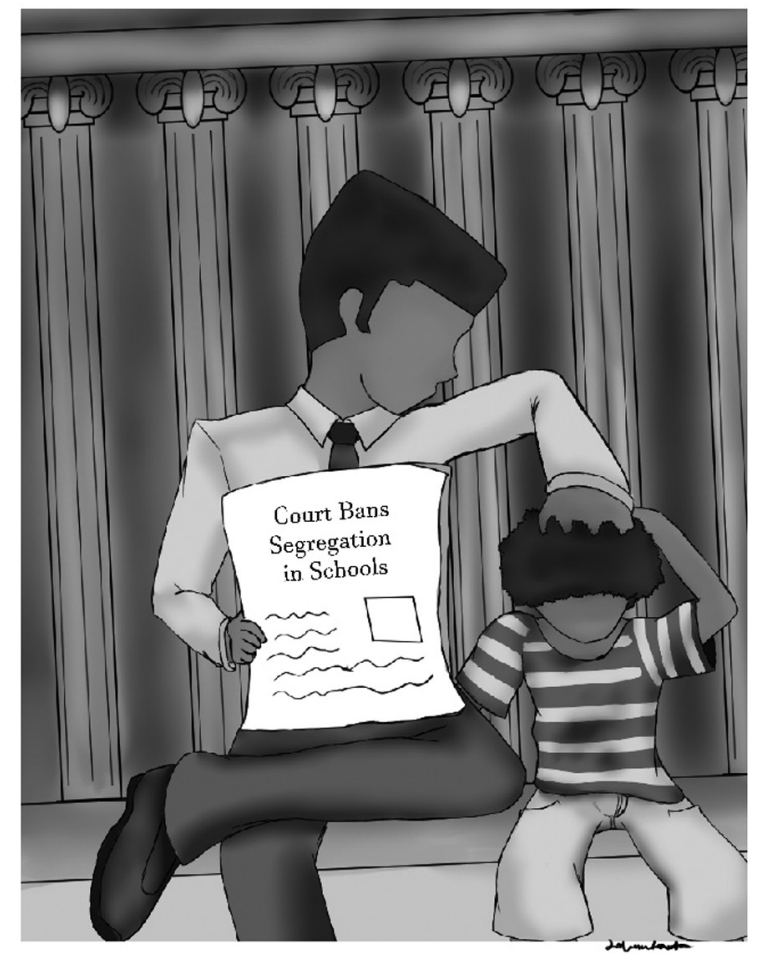

FIGURE 4.1 Brown v. Board of Education: A hopeful day.

SOURCE: Illustration By Jalance Foxworth. 


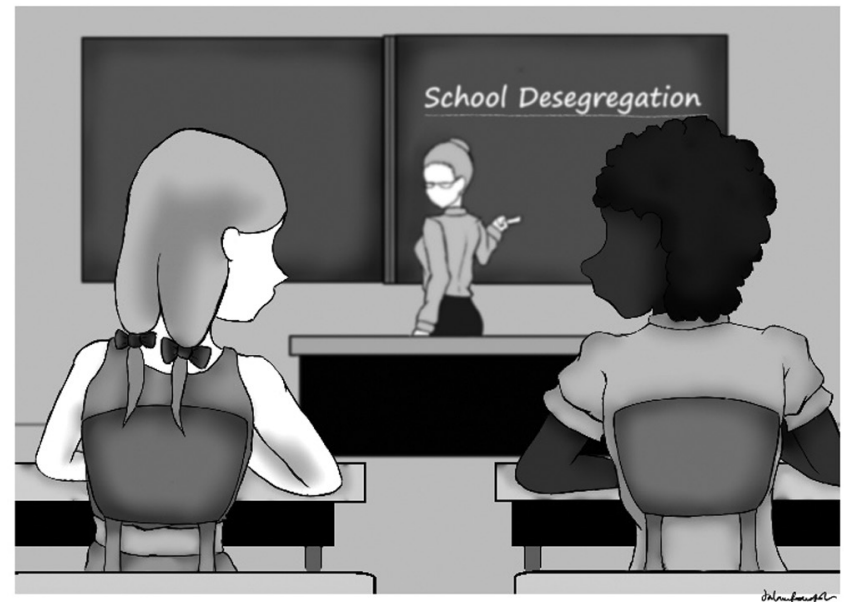

FIGURE 4.2 School desegregation.

SOURCE: Illustration By Jalance Foxworth.

schools (McCardle \& Bliss, 2019). This phenomenon is known as White flight. Schools, in fact, are more segregated now than they were 40 years ago. This segregation contributes to the achievement or performance gap, and Black students are much more likely than White students to attend high poverty schools.

Despite the hope of Brown v. Board of Education, social, ethnic/racial, demographic, financial, and institutional practices contribute to the ongoing entrenchment of segregation. McCardle and Bliss (2019) outline a series of the negative effects stemming from [de facto] segregation(see Figure 4.3).

Practices such as redlining, unfairly discriminated against Black, Indigenous, and people of color (BIPOC) communities by denying financial services (fair pricing, access to loans) to individuals based on their race to prevent racially mixed neighborhoods (desegregation). Unfair housing practices contributed to white flight ultimately leading to racially isolated communities enforcing the persistence of school segregation. Schools in predominantly African American or Black communities are left underfunded leaving them bereft of adequate resources. The lack of adequate funding and resource deprivation contribute to achievement gaps (McCardle \& Bliss, 2019). McCardle and Bliss (2019) further assert that "this in turn leads to greater achievement gaps, while also reinforcing stereotypes that students of color are less capable and that integrated schools will lead to a decline in academic rigor" (p. 115).

Another structural issue pertains to the disproportionate numbers of students from racially, culturally, and linguistically diverse (RCLD) backgrounds overrepresented in special education. In fact, this overrepresentation has been an issue that dates to the 1960 s. According to Kulkarni (2020), there are several reasons for the overrepresentation of students of color in special education:

1. Systemic racism that exists in school systems-systemwide racist practices affect students from RCLD backgrounds. Many of these practices lead to the overrepresentation of students from RCLD backgrounds, especially when they are not viewed from a strengths perspective. 


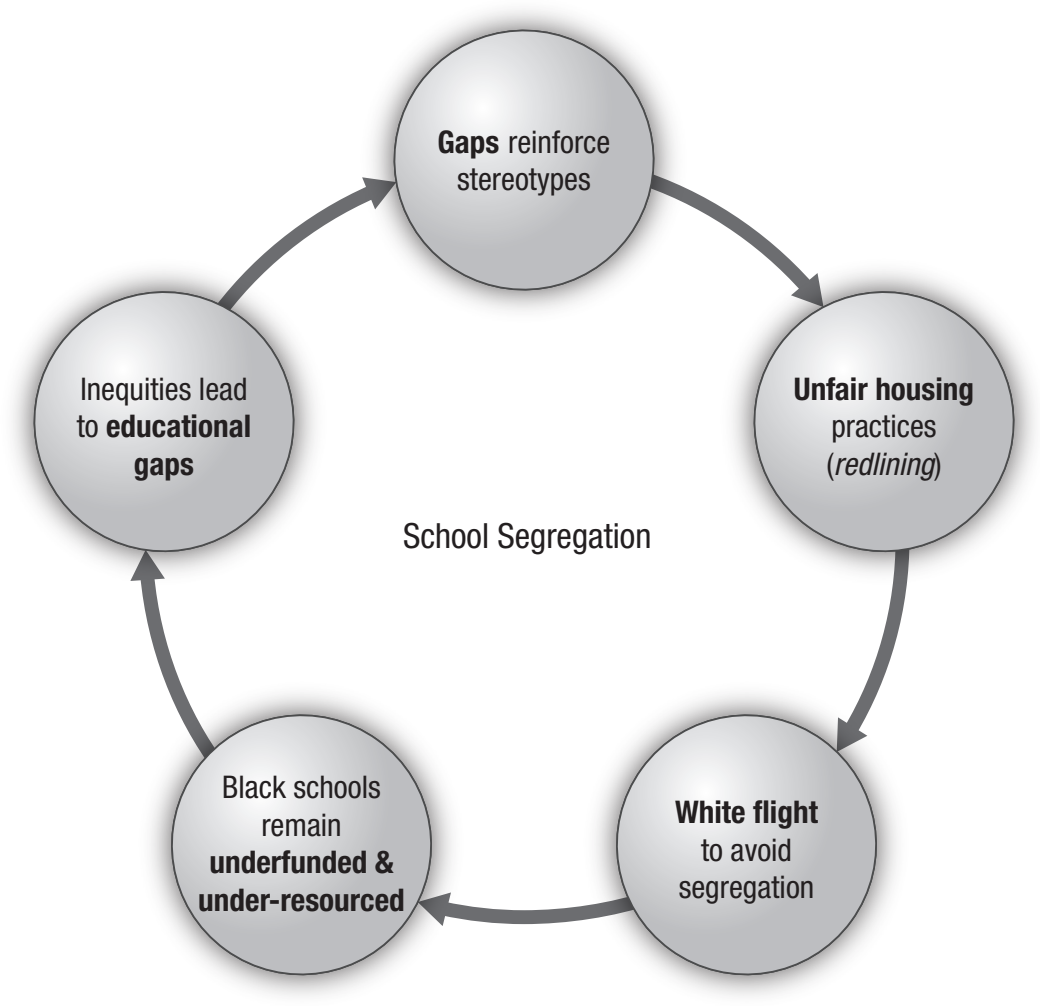

FIGURE 4.3 The entrenchment of school segregation.

SOURCE: McCardle, M., \& Bliss, S. (2019). Digging deeper: The relationship between school segregation and unconscious racism. Smith College Studies in Social Work, 89(2) 114-131. https://doi.org/10.1080/00377317.2019 .1686929

2. Schools represent colonial spaces-the hegemonic stance and ideological positioning that requires an unencumbered process of assimilation (where migration/ immigration is concerned). This new neocolonial attitude has become the tool by which many students are excluded from regular education.

3. Intersections of race combined with poverty and health outcomes-were viewed as attributable to an overrepresentation in special education. Poor and vulnerable people are not often assessed from the strengths perspective or in light of their intersecting oppressions.

Further noted in the literature is an overrepresentation of English learners (ELs) in special education programs across the United States (Clark-Gareca, 2020; Kulkarni, 2020; Morgan et al., 2018; Umansky et al., 2017). Students whose first language is not English and those who require additional support are more likely to be overrepresented in special education services as well. Kulkarni (2020) suggests that future research explores the intersection of "dis/ability and race as it relates to education" (p. 13).

Social workers are uniquely skilled and positioned to challenge status quo practices and to promote equity, even in secondary settings. School social workers must eschew 
racist practices and recognize the persistence of deficit-oriented views of students/ families. In particular, Stone (2017) reminds us of the need to have adequate representation of African Americans in education, specifically within the profession of social work. This represents a matter of equity and inclusion. To address racial inequities in school structure, school social workers must operate from an equity-minded stance. Being equity-minded means having an awareness of how institutional practices can promote equity and inclusion and diminish the effects of cumulative disadvantage and oppression.

\section{SCHOOL SOCIAL WORK PRACTICE ROUTINES}

Sue and colleagues (2015) assert that social justice concepts for social work practice include utilizing key frameworks, such as ecosystems, strengths-based, critical theories, and antiracist perspectives.

\section{Ecosystems and School Social Work}

School social workers operated within an ecosystems framework early on as visiting teachers (Sherman, 2016). School social workers intervened by engaging with the community to address school behavior and attendance issues and to inform parents of educational requirements and available resources. Sherman further asserts that because the school social workers' role was to work with at-risk students, their position was often devalued in the school system. Social workers must advocate for a more integrated role and be willing to take leadership roles within school systems to effect change.

School social workers must understand their unique skill set, market their services, and advocate for fair practices within schools. This also means, understanding what is often "taken for granted" (Stone, 2017, p. 1240) in everyday practices. School social workers should strive to utilize all levels within the ecosystems framework and draw on their understanding of context as they practice in schools.

Lee and colleagues (2020) provide several suggestions for school social workers to enhance their practice routines. Consider how the following may help school social workers promote racial and educational equity and social justice in school settings: Consider the case scenario of Ms. Kate and Maye from the beginning of this chapter. Looking at Table 4.1, how might Ms. Kate use self-reflection to promote social justice? How can Ms. Kate promote social-emotional learning goals/standards for all students in the classroom? It is important to develop the professional habit of self-reflection if school social workers are to honor the spirit of diversity, equity, and inclusion in their practice.

\section{Strengths-Based and Systems Perspectives}

The strengths-based perspective can be integrated into the school social worker's daily practices. The strengths perspective refutes a deficit-laden, pathology-based perspective. Saleebey (2009) introduced the strengths-based perspective in acknowledgment of two main beliefs: (a) that all people, all environments, all communities possess strengths, talents, resources, and abilities "that might not be recognized or used, or are underused" and (b) "that all people are capable of growth and change" (Lee et al., 2020, p. 3). 
TABLE 4.1 School Social Work Practice Routines for Enacting Racial Justice and Equity

\begin{tabular}{|c|c|}
\hline LEE ET AL. SUGGEST: & KELLER AND GRUMBACH SUGGEST: \\
\hline Promoting social justice & $\begin{array}{l}\text { School social workers should reflect on social justice in the as- } \\
\text { sessment of one's daily activities as a starting point. }\end{array}$ \\
\hline $\begin{array}{l}\text { Promoting racial and educa- } \\
\text { tional equity }\end{array}$ & $\begin{array}{l}\text { School social workers should engage in advocacy efforts to pro- } \\
\text { mote awareness about the overrepresentation of students of } \\
\text { color in special education, engage in fair practices, and call } \\
\text { attention to social, educational, and disciplinary injustices. }\end{array}$ \\
\hline $\begin{array}{l}\text { Engaging in case } \\
\text { management }\end{array}$ & $\begin{array}{l}\text { School social workers already engage in case management (in } \\
\text { many schools) but may need to revisit their policies on home } \\
\text { visits and increase community engagement efforts/initiatives. }\end{array}$ \\
\hline $\begin{array}{l}\text { Facilitating collective parent } \\
\text { involvement. } \\
\text { e.g., door-to-door outreach, } \\
\text { persistence, passion, re- } \\
\text { sponsiveness, and informa- } \\
\text { tion and resource linkages. }\end{array}$ & $\begin{array}{l}\text { School social workers may also engage in key stakeholder in- } \\
\text { terviews, identifying a parent in the community to serve as a } \\
\text { liaison to other parents/groups within the community, and by } \\
\text { holding resource fairs to assist students/families. }\end{array}$ \\
\hline $\begin{array}{l}\text { Collaborating with teachers to } \\
\text { promote student strengths }\end{array}$ & $\begin{array}{l}\text { School social workers can play a key role in addressing } \\
\text { social-emotional learning goals/standards in the classroom. } \\
\text { Collaborating with teachers may help in the promotion of } \\
\text { prevention efforts in the school one classroom at a time. }\end{array}$ \\
\hline $\begin{array}{l}\text { Conducting prevention-based } \\
\text { interventions }\end{array}$ & $\begin{array}{l}\text { School social workers can work toward prevention not only by } \\
\text { assessing the school climate and addressing specific issues, } \\
\text { such as bullying, discrimination, and oppression, but also by } \\
\text { facilitating conversations about inclusion among staff and } \\
\text { broadly educating students, parents, and the community } \\
\text { around treating others with respect. }\end{array}$ \\
\hline
\end{tabular}

According to some scholars, these beliefs as in the systems perspective (Lee et al., 2020) recognize the dynamic nature of systems (i.e., change is constant). There is always an interplay of "ups and downs" (Lee et al., 2020. p. 3) in any system. Although people may experience many problems there is a vacillation between the problematic and calm times in the lives of the people we serve. As Lee and colleagues (2020) assert, "these 'ups' become exceptions and represent the 'unnoticed' strengths, potential, and resources" (p. 3) of clients' experiences. When social workers employ the strengths perspective, they understand and utilize the unused potential and resources of clients as they engage them in the helping relationship and change process. Problematic behavior, life challenges, and adverse experiences present opportunities for growth.

Moreover, utilizing a strengths-based practice approach in a school environment is a way to support students by helping them recognize and draw on their strengths in a way that aligns with their aspirations. If students have yet to identify or realize their own aspirations, this may become the starting point that leads to alignment with their treatment goals. Utilizing strengths-based practice as a school social worker may encompass the following:

1. Engaging students in collaborative ways

2. Exploring and making note of students' perceived strengths, talents, resources, and experiences 
3. Exploring problem-free times and space-times of coping and resilience (i.e., what things look like when they experience the "ups"-times of calm when they are problem-free)

4. Engaging students in ways that use their talents and strengths to address the problem

5. Assessing with students and their progress in light of newfound or underutilized strengths

6. Assessing students' awareness of the helping process and what to do if they are in need of counseling again (in anticipation of termination)

\section{WORKING WITH DIVERSE FAMILIES}

When you think about the well-being of children, two of the social institutions that are central to their lives are, first, families and, second, the schools. When those two systems work collaboratively, children manifest more positive outcomes. There are broad benefits for parental involvement in their children's education, including stronger parent-teacher relationships; better school attendance; more positive behavior, attitudes, and mental health of children; greater parental confidence and satisfaction (Hornby \& Blackwell, 2018); greater educational attainment, with better academic performance (Blair, 2014; Jeynes, 2007); improved behavior at home and school, better social skills; higher scores on standardized tests; and better adaptation to the school environment (Henderson \& Mapp, 2002). Thus, you, as a social worker, will want to work to create a collaborative relationship between parents/caregivers and the school. However, it is important to account for different understandings of parental/caregiver involvement, based upon culture and individual life experiences. Volunteering in the classroom and participating in the Parent Teacher Association are not the only, or even the best, ways of being involved in children's education. It also is important to acknowledge that not all families or parents/caregivers are treated equally in their interactions in the school setting. Being able to connect with families and to help school staff identify and affirm the strengths of these families will enhance the experiences of the children and youth they serve.

The school social worker will work with many families, each with unique life experiences and trajectories, as well as individual perspectives based on current and past experiences with schools. Family perspectives may be influenced by their own past experiences in school settings, their children's experiences, friends, and community, as well as media portrayals of the school system. They also will bring different cultural understandings of their role as parents/caregivers in interacting with the school. It is important to recognize and reflect the strengths of families, validate their experiences, and support them in helping their children succeed in the school environment. Most parents do want the best for their children and want them to be successful in school, even if they recall an unjust past of their own. Hill and colleagues (2018) note that parents of color highly value education and want their children to be successful, even while understanding the structural racism and inequality that create barriers to success for their children.

It is crucial to understand how past negative experiences impact the ways in which families engage with school systems in the present. The traditional makeup of the family 
has changed dramatically from the concept of the nuclear family of the past. School social workers understand the diversity that exists in families today. Families comprise many different forms:

- Single mothers/single fathers

- Two-parent families (same sex, heterosexual, or nongender conforming)

$\square$ Mother/Father

$\square$ Mother/Mother

$\square$ Father/Father

- Grandparents raising grandchildren

- Kin caregivers (siblings, aunts, uncles, cousins, etc.)

- Adoptive kin

- Foster families

- Stepfamilies or blended families

- Cohabitating families (with no legal ties)

- Extended family or multigenerational families

Families are not formed as archetypes (as in the past) and they may continue to evolve in unforeseen ways in the future. Families are not defined by marital or legal status, nor are they defined by bloodline alone. Families are diverse in many ways. Diversity refers to recognizing differences and encompasses the variety of humankind.

\section{CULTURAL COMPETENCE CONTINUUM: INCLUSION AND HUMILITY}

Inclusion is defined as embracing all as equal participants, recognizing the unique strengths and contributions that people bring to their communities, and ensuring that mechanisms are in place for equitable participation. Inclusion suggests that all voices are present and heard.

Cultural competence (CC) and cultural humility $(\mathrm{CH})$ are not necessarily mutually exclusive. In fact, cultural competence is dynamic and ever-evolving and develops along a continuum (Cross et al., 1989; i.e., the Continuum of Cultural Competency or CCC). Cultural competency is a term that sometimes brings critique as it suggests that the practitioner is an expert on culture (reaching a completed point), and as you know, it is impossible to be fully competent in all existing cultures. Cultural humility brings an openness and willingness to learn on the part of the practitioner, who is viewed not as an expert but rather as a continual learner of diverse cultures. The position of humility incorporates a willingness to question one's own assumptions, reflect continuously on personal biases, and cultivate self-awareness. $\mathrm{CH}$ also affirms the experiences of diverse others and the tremendous strengths that all individuals and communities possess. Barsky (2018) writes that indicators of cultural competency include social workers' continual development of cultural awareness and knowledge about family traditions and values. Barsky further asserts that all aspects of one's identity, including immigration status, religion, sexual orientation, gender expression, ability status, social class, and ethnicity are forms of cultural expression. 
Cultural awareness begins as social workers employ an inwardly focused exploration of self. That is social workers should examine their own cultural identity and characteristics to understand their own worldviews, values, language usage, traditions, and norms. Social workers are also open to exploring the cultures of those they serve (Barsky, 2018). There is an interplay between culture and how the client presents in treatment. As an example, Barsky (2018) notes when clients experience depression it is important for social workers to be aware of the meaning depression has in their culture. Specifically, Barsky states that social workers should be aware of the type of intervention and support that is most relevant or appropriate based on the person's culture. School social workers should be aware of how students and their families engage in help-seeking and how students participate in social work services.

Barsky (2018) also reminds social workers of the need to employ cultural sensitivity or what Keller and Grumbach prefer to think of as cultural empathy. Social workers must seek to understand their client's experiences from their context even when the social worker has no firsthand experience of what the client encounters. "Accordingly, if I am working with a woman who wears a hijab or headscarf, I strive to consider the meaning of the hijab or headscarf from my client's cultural and individual perspectives, rather than from an outsider's perspective" (Barsky, 2018, para. 11).

$\mathrm{CCC}$ and $\mathrm{CH}$ work together in a dynamic process to reach a level of cultural responsiveness that develops over one's personal and professional life. In brief, $\mathrm{CCC}$ and $\mathrm{CH}$ refer to the ever-evolving ability to interact effectively with diverse others in a respectful, open, and flexible way and having a commitment to do antiracist work. It is important for social workers to become aware of their own perspectives and privilege. To understand and engage with clients who lack privilege, you must understand how you benefit from privilege whether knowingly or unknowingly. "You cannot dismantle what you cannot see. You cannot challenge what you do not understand" (Saad, 2020, p. 38). You also must continuously question your perspective and come to terms with your own biases, knowing that everyone possesses biases and that it is impossible to be raised in a racialized world without internalizing some of the disparate notions of race, ethnicity, and culture. You must find ways of managing these biases and stereotypes. Culturally responsive practice requires you to take action and avoid silent complicity and avail yourself of training opportunities about aspects of human diversity.

One of the early understandings of White privilege comes from the work of Peggy McIntosh (1989). McIntosh shared her insights on White privilege, as she reflected on the belief that racism emanates only from individual acts without any acknowledgment of the ways in which all White people benefitted from larger, structural circumstances that favored their skin color. Furthermore, Whites are taught to think of themselves as morally neutral and normative and not to consider the ways in which they experience privilege. In essence, unexamined privilege means not having to worry about or even consciously think about one's racial identity in one's daily life.

\section{POPULATIONS FACING INEQUITIES IN SCHOOL SETTINGS}

The U.S. Department of Education was promoted by President Jimmy Carter and established by Congress in 1980. President Carter emphasized the importance of education and called for the creation of a separate department to administer federal educational policies. 
The mission of the Department of Education "is to promote student achievement and preparation for global competitiveness by fostering educational excellence and ensuring equal access" (U.S. Department of Education, n.d.-b, para. 1). As we have seen, however, schools have not consistently met this mission, particularly in terms of ensuring equal access to quality education. Some populations of children are privileged in the public school system and others face exclusion, oppression, and disadvantage. The most obvious and clear examples of exclusion and oppression are based upon race/ethnicity (as discussed earlier). In addition, other groups of children face inequities and other challenges in the schools, including students experiencing poverty, homelessness, foster care, as well as those receiving special education or EL services. It is important to recognize that these are not discrete groups of students; there are many overlapping or intersecting dimensions.

\section{CHILDREN EXPERIENCING POVERTY}

In the United States, nearly one in seven children in 2019 lived in poverty (Children's Defense Fund [CDF], 2021). Since the pandemic, October 2020 data show an additional 8 million Americans, including 2.5 million children, have fallen below the poverty line (Parolin et al., 2020). As a consequence of a sluggish economy due to the pandemic, the children's poverty rate increased from $18.7 \%$ to $20.4 \%$ from January to September 2020, one in five children (Parolin et al., 2020).

The underlying principles of democracy are that each person has a voice, equal to that of any other; that anyone can work hard and achieve. In reality, the United States, compared to other industrialized nations, has lower social mobility, higher rates of childhood poverty, and greater income inequality (McCarty, 2016). This provides the context within which schools are situated; additionally, schools are part of this context and perpetuate these inequities. Children represent the largest age group among people in poverty; in other words, they have higher poverty rates than other age groups. Additionally, children and youth of color are disproportionately overrepresented among the population of children in poverty.

Poverty can have a significant impact on one's school experience and educational outcomes, which are carried into adulthood. Poor children are more likely to have lower academic achievement, less likely to complete high school, and have fewer employment prospects than middle-class children (CDF, 2021). See Figure 4.4.

The cycle of poverty begins before birth. Children from impoverished homes face challenges even in the womb. Low-income mothers may be less likely to receive consistent prenatal care and adequate nutrition during pregnancy. This could lead to complications during pregnancy that may not be addressed until delivery. Inadequate nutrition during pregnancy can also lead to smaller birth weight and may hinder prenatal development. In children's early years, inadequate nutrition may continue to impact their development in negative ways. For instance, brain development is significant during the infant, toddler, and preschool stages, and nutrition has a bearing on this. Although programs like WIC (Women, Infants, Children) exist to address some of these concerns it is not sufficient in and of itself. Problems persist when parents are unaware of WIC and when parents do not access the resources for the entire benefit period. Despite the benefits of WIC services like supplemental foods, nutritional education, and referrals for health care, there are many 


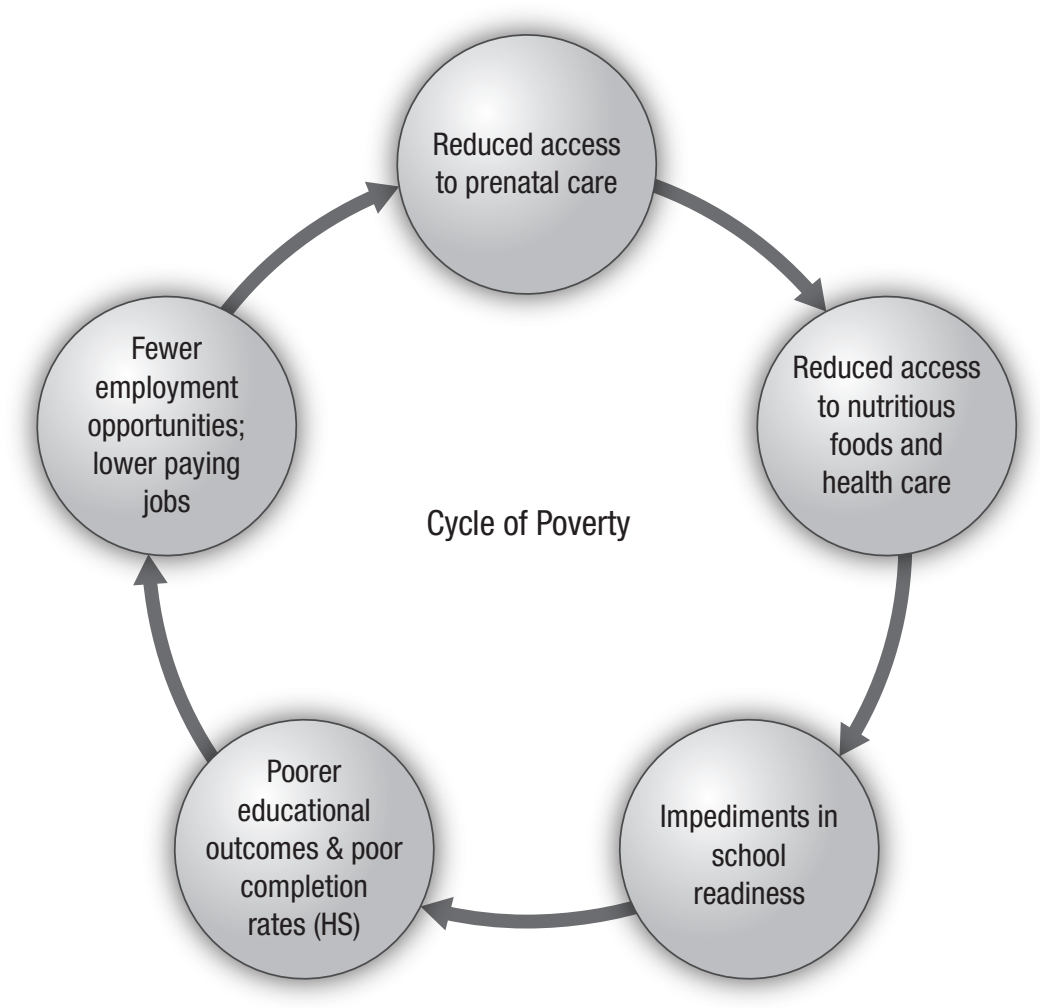

FIGURE 4.4 Cycle of poverty highlighting the role of education.

other aspects of poverty related to housing, environmental stimulation, and access to other services that also affect the developing child. Also, children in poverty often come to school less prepared, perhaps not having the opportunity for enrichment activities, such as preschool or sports and social activities. Although Head Start seeks to level the playing field for preschoolers, not all children eligible for Head Start are able to receive the services due to inadequate funding. Some states have implemented a state version of early intervention, but again, not all children are able to take advantage of this. Once in school, children from low-income families may not have the same access to academic support. They may attend schools that are under-resourced. Teachers may hold unconscious biases about certain children's ability to achieve. Parents may be working multiple jobs or be engaged in shift work, and may not be as readily available to help their children with school work. All these circumstances may lead to lower academic achievement, including lower test scores and decreased likelihood of completing school and pursuing college. Lower educational attainment can have significant effects on employment possibilities in adulthood, ultimately continuing the cycle of poverty. A cycle can become generational if it is not broken. If that cycle is negative, it affects multiple generations in adverse ways. Thus, the challenge is in finding a way to break the cycle and interrupt this progression toward continued poverty. As you can see, education certainly has the potential to interrupt this cycle but has not always lived up to this potential. Social workers are in a position to address some of the barriers presented by poverty so that this cycle can be broken. 


\section{REFLECTION QUESTIONS}

1. What is the responsibility of the school social worker in supporting children from lower income families?

2. Do you think that children from low-income households may face some implicit or explicit bias and discrimination in the schools? What forms may this discrimination take?

3. How can you, as a social worker, advocate for this population of children?

4. What do you see as ways of breaking the cycle of poverty? What is the role of education in breaking this cycle?

\section{CHILDREN EXPERIENCING HOMELESSNESS}

The U.S. Department of Education (2016b) identifies the plight of highly mobile students. Transient students of concern are those with disabilities, from military families, from migrant families, living in foster care, and those who are homeless or housing insecure. The National Center for Homeless Education (2020) reports that the number of homeless students is over 1.5 million and growing and that this number is likely an undercount. This population of children and youth encompasses a range of living circumstances, including living in shelters, living in the family vehicle, living in homeless camps, sharing households, and, in the cases of youth, couch surfing. The reasons for becoming homeless are equally varied and may include intimate partner violence (IPV), other parental separations or conflicts, loss of employment of a parent, serious illness of a family member, generational poverty, substance use, and in the case of youth, abuse, neglect or other parent-child conflict. Unaccompanied homeless youth have increased in numbers; youth of color and LGBTQ + youth are disproportionately represented in this population.

The stresses experienced by children who are homeless, including frequent mobility with a lack of connections to school and community, can lead to health and mental health concerns, behavioral challenges in the school setting, increased absences, more negative educational outcomes, inconsistency in school participation, embarrassment, and a lack of connection to peers (U.S. Department of Education, 2016). Again, children of color, particularly African American, Native American, and Pacific Islanders make up a disproportionate percentage of the homeless population compared to their percentages in the total U.S. population. Homeownership is one of the best pathways to accumulating wealth in the United States. Homeownership rates are much higher among White populations than Black populations, due in large part to historic discriminatory practices that limited access to mortgages and to certain communities. Within the United States, the wealth gap is even greater than the income gap.

The school social worker can assist children and youth experiencing homelessness in making the adjustment to the school setting, as well as advocating for the rights of these students, facilitating as much educational stability as possible, and assisting families in securing resources. Some students may have experienced trauma before and during their experience with homelessness. The school social worker can be instrumental in supporting 
such children. Stone and Uretsky (2016) suggest that McKinney-Vento overemphasizes access to school rather than stressing the quality of education and opportunities available to these students. They further recommend creating connections among staff, parents, and community partners, as well as the provision of intensive case management with families. The U.S. Department of Education (2016b) also recommends creating a welcoming environment; building trust with students, sensitively identifying and supporting students; ensuring that school and classroom policies and procedures, particularly disciplinary policies, are fair to homeless students; and connecting homeless students and their families to community resources.

\section{CHILDREN AND YOUTH IN FOSTER CARE}

Well over 400,000 children are in foster care in the United States, based on the point-intime count (Children's Bureau, 2021). Of these, roughly 270,000 are school age, 5 to 17 years (U.S. Department of Education, n.d.-a). Children and youth in foster care experience poorer educational outcomes than their peers not in care (National Working Group, 2018) and are more likely to drop out of school and less likely to attend or graduate from college (U.S. Department of Education, n.d.-a). When thinking about the challenges faced by this group of children, it becomes apparent that they have had to adjust to being removed from their homes, having another parent figure with a new set of rules and expectations. Often, there is a change in school and community. This may require making a new set of friends. Children and youth may feel self-conscious and embarrassed about being in foster care which can affect their adjustment to the school setting. The school social worker can assist by meeting with the student, parent/caregiver, and child welfare worker to discuss the child's adjustment and well-being. In addition, the social worker helps the parent/ caregiver understand what to expect in accordance with the student's chronological age and developmental level. The social worker may be the key person to create a welcoming environment for the child and foster family.

Child welfare is another area of notable disproportionality based on race. African American and Native American children, in particular, are overrepresented in the foster care system. At each stage of the child welfare process, these racial and ethnic groups are overrepresented, beginning with the number of calls made in reporting abuse and neglect, the percentage of reports being "indicated," the decision to remove children from their families, and the decision to keep children from returning to families. Although this has been a concern for a number of years, and although many state welfare agencies have sought to address this through training and education, racial disparities continue to exist. At a pointin-time measure, on September 30, 2019, of the estimated 423,997 children in foster care, 44\% were White, 23\% were Black or African American, $21 \%$ were Latinx, $8 \%$ were multiracial, and 2\% were American Indian/Alaska Native (Children's Bureau, 2021). School social workers should be aware of the ways that minoritized populations are overrepresented in these interrelated systems (schools, child welfare). School social workers understand how bias may contribute to critical decision-making, especially as it affects the lives of students and their families. As mandated reporters and concerned professionals, we have an obligation not only to protect children but also to do so in an unbiased manner to promote culturally responsive care in school settings. 


\section{STUDENTS WHO ARE IMMIGRANTS AND/OR REFUGEES}

As with other populations of children, each person's experience is unique. Immigrant and refugee students, as well as U.S.-born children of immigrants, are no different. Each will have had a different path and different personal and family experiences. Some children and youth have entered as immigrants, through a relatively smooth process; others have come as refugees and asylees; still others are not documented. And some are children of immigrants, though not immigrants, themselves. Those at greatest risk in the larger society, as well as in the school setting, include ELs, children from low-income families and/or mixed-status families, recent arrivals, and undocumented immigrants (Rodriguez et al., 2020). Teasley and colleagues (2017) estimate that in the United States, approximately 5 million children and youth have at least one parent who is undocumented. This, depending on the age of the child and local political climate, can lead to increased stress for children, who may be worried about their parents and possible deportation of and separation from parents. It is important to understand the level of fear these students may experience and to recognize the additional work required in developing trust with these students. Children who are refugees, as well as those who are undocumented, may have experienced significant trauma before and during their journey to their new country. Some children may have been born in refugee camps and this is all they have known. While some refugees may have experienced war and the loss of their home and loved ones (family members) others' experiences may be different. For instance, global climate change migrants refer to those who have been forced to leave their countries because their land will no longer sustain farming due to extreme heat, extended periods of drought, and other climate change-related factors. For many children in these circumstances, their education has been disrupted and they may be years behind their peers. This phenomenon of migration is global, as child displacement continues to grow; approximately 33 million children under age 18 are displaced globally, approximately half being displaced internally (meaning displaced within their home country). Of the remainder, more than 13 million children are refugees and an additional million are seeking asylum (UNICEF, 2020). Thus, many countries need to educate these children who may have experienced so much trauma. Even those who migrate willingly and enter with documentation often feel a sense of grief and loss for the country, home, and community they left behind. Additionally, they may now feel like they don't totally belong anywhere-no longer part of their home country, but not fully accepted into their new country. Children who are immigrants are at increased risk for mental health challenges, such as anxiety and depression; additionally, they may have lower self-esteem, not surprising as they experience more frequent teasing and bullying. Finally, they are less likely to complete school than their nonimmigrant peers (Teasley et al., 2017).

Schools in many ways represent a microcosm of the issues present in society as a whole. The political climate can have a clear effect on children and youth. As an example, students with diverse linguistic and religious backgrounds can experience discrimination. Those who work in schools need to be aware of thesociopolitical context and the ways it 
can spill over into the school (Teasley et al., 2017). Social workers, like everyone else, function within the confines of the school and also bring their own biases and positionality, and these factors may affect how they deliver services to immigrant students (Rodriguez et al., 2020). Rodriguez and colleagues use the concept of "nepantlera," a word derived from the Nahuatl word nepantla, meaning "in-between," to describe the role that school social workers can play in their work with those children and youth who are in-between in terms of their own identity and positionality. The term nepantla has been used by Gloria Anzaldúa, in Borderlands/La Frontera: The New Mestiza (1987).

The nepantlera is a person who goes among multiple worlds without allegiance to any and can be a bridge between worlds. Applied to schools, this involves the personal transformation of the social worker in their ways of knowing and being and in moving toward societal transformation. School social workers act as connectors by obtaining needed resources and connecting students and their families to community resources. School social workers also positively influence the school system by calling for it to value rather than dismiss or marginalize immigrant students (Rodriguez et al., 2020).

School social workers can bring an understanding of the ways power and privilege at multiple systemic levels, including school and community, can affect the daily life of students who are immigrants. Social workers can advocate for these students and at the same time expand their own level of awareness of the barriers these students face (Rodriguez et al., 2020).

\section{English Learner Programs}

One subgroup of immigrant and refugee students are ELs, those students participating in English-language programs. Approximately 10\% of the public school population are ELs. These students often face additional layers of discrimination. Schools can provide a sense of belonging and opportunities to build social capital for those students who may be discriminated against outside the school setting (Rodriguez et al., 2020). Policies under Title III of the Elementary and Secondary Education Act (reauthorized in 2015 as the Every Student Succeeds Act [ESSA]) cover education for EL students. School districts must have procedures in place for the timely identification of students in need of EL services, often through a language survey upon enrollment, then valid and reliable testing of those for whom English is not their primary or home language. ELs must have services provided by qualified educators so that they can access the general curriculum. Students who are English-language learners must also be allowed access to all other programs, including those for gifted students as well as special education services. ELs' English proficiency is measured each year to ensure that they are making progress and can be exited within a reasonable time, although they do not exit until they demonstrate proficiency. In addition, they are followed for 2 years after they leave the EL program to make sure they were not exited too early (U.S. Department of Education, n.d.-c). School social workers, particularly in schools with high numbers of ELs, should be well versed in the rights of EL students and their families. 


\section{Long-Term English Learners}

Although ESSA does not formally define long-term ELs, local education agencies (LEAs) receiving Title III grants to assist EL students in acquiring English language proficiency (ELP) and to meet achievement standards must report the number and percentage of ELs who are not meeting ELP within 5 years of first being identified as an EL and enrolling in the LEA (U.S. Department of Education, 2016a). Thus, those who remain in EL programs beyond 5 years may be considered long-term ELs. It is incumbent on LEAs to examine possible reasons for difficulty in acquiring ELP. These reasons may include an inadequate curriculum or the presence of a disability or other challenges with the student. Because progress is monitored annually, if an EL is not progressing, the LEA may explore other services, following the Multi-Tiered System of Supports (MTSS) model. Long-term ELs who remain for extended periods of time may face additional challenges, including not attaining ELP and not graduating from high school or being college- or career-ready (2016a). The school social worker may be able to play a role in ensuring that such students do complete high school and are prepared for post-high school activities.

\section{STUDENTS WITH DISABILITIES}

Students with disabilities often face several challenges within and outside of the school setting. It is important that students with disabilities be seen as students first. Students with disabilities are entitled to a free and appropriate education within the least restrictive environment and should be provided services through an individualized education program (IEP). This means educational services must be provided and designed to meet their specific needs to prepare them for additional education, employment, and independent living so that they can reach their full potential. For students to qualify for special education services, they must have a specific disability (there are 13 categories of disability identified in the Individuals with Disabilities Education Act [IDEA]) that causes an adverse educational impact and requires specially designed instruction (SDI) and related services. Students with disabilities should not be segregated from the general student population and should be in the setting that is most similar to that of the general school population where they can still be successful.

Sometimes students with disabilities are teased or bullied by peers. It is important to advocate for students with disabilities, to teach them skills in self-advocacy, to inform parents of their rights, and to educate the general population of the school about disabilities and about the strengths that students with disabilities have. Oftentimes, people with disabilities are treated as though they are less capable than they really are or are treated as though they have a cognitive impairment when they do not. This can translate into adulthood, as well, where they may be unemployed or underemployed simply because people discount their abilities.

With the advent of the COVID-19 pandemic, students with disabilities did not consistently receive the SDI to which they were entitled. School districts reported difficulties in meeting the needs of students with disabilities, particularly true in lower income districts, where accessing remote instruction was more challenging in general (American Institutes for Research [AIR], 2020). 


\section{LGBTQ+ STUDENTS}

Youth who identify as LGBTQ+ face discrimination in the school setting, as well as in society as a whole. They are more likely to experience stress, fear, verbal and physical harassment, physical assault, than their peers (Kopels \& Pacely, 2012). They are more likely to experience bullying and have poorer educational outcomes. According to the Centers for Disease Control and Prevention (CDC, 2018), sexual minority youth are at increased risk for substance use, which includes specific illicit drugs, injecting drugs, and misusing prescription opioids. They also are more likely to experience physical threats, electronic or personal bullying, and dating violence and to report feeling unsafe at school (CDC, 2018). They are at greater risk of developing mental health issues, including feeling sad or hopeless, seriously thinking about suicide, making a suicide plan, attempting suicide, and being seriously harmed in a suicide attempt (CDC, 2018). All these concerns are intertwined with their experiences at school, their support or lack of it at home, and sorting out their identity during adolescence.

Sexual minority youth may come from nonsupportive households and may look to their peers for acceptance and look to adults in the school to provide a safe space. However, school often does not feel like a safe space, and many sexual minority youth miss school because of their fears about how they will be treated (CDC, 2018). School social workers can intervene on many levels. They can work to change the school climate. This may include working with administrators, teachers, parents, and students (Kopels \& Pacely, 2012). As members of the MTSS team, they also may educate teachers and students about what bullying looks like, using Tier 1 interventions focused on teaching positive behavior schoolwide. They can be supportive of gay-straight alliance organizations (2012).

Each of the mentioned populations is stigmatized in some way. One of the Grand Challenges for Social Work is to achieve equal opportunity and justice (Grand Challenges for Social Work, n.d.). To that end, Goldbach and colleagues (2015) produced a working paper identifying the importance of reducing stigma. They have identified the role stigma plays in disadvantaging populations deemed to be different, the social and personal costs of stigma, and the mechanisms by which stigma plays out in people's lives. They further identify ways in which stigma has been reduced among some populations, suggesting that stigma can be reduced or eliminated (Goldbach et al., 2015). School social workers are uniquely poised to address stigma in the schools because of their skill set and role. Social workers have a long-standing concern for social justice, an understanding of the effects of stigma, and a focus on populations that have been stigmatized. Goldbach and colleagues (2015) make several recommendations, pertinent to reducing stigma in school settings, such as antibias training, professional training, addressing inequitable policies, and self-reflection, as well as reflecting on the profession of social work as a whole (i.e., any role it has played in maintaining stigma as well as how the profession is perceived by stigmatized groups).

\section{IMPORTANCE OF SELF-AWARENESS}

With so many diverse populations of students within the school setting, school social workers are called to provide equitable and inclusive services to all and to promote social justice. It is important for school social workers to become consciously aware of their beliefs, values, 
and reactions toward different aspects of diversity, intentionally seeking to recognize their own personal biases. Keller and Grumbach suggest that school social workers develop the discipline of reflective practice to identify and confront personal biases. Reflective practice includes developing a habit of self-reflection, creating a space for examining one's true self and how that impacts professional decision-making. Personal values, biases, and opinions are shaped by positive and negative experiences and the interpretation of those experiences. Social workers must, despite being fully human and prone to biases, challenge their perceptions to ensure that they are based on truth and not solely on subjective experiences or stereotypes. School social workers must explore their feelings and beliefs about diverse others. Professionals should have a natural curiosity about diverse others and truly embrace difference in practice (i.e., a reciprocal difference, not a subordinated difference or other than the mainstream viewpoint or experience).

Hartwell and colleagues (2017), in their paper on equity, diversity, and inclusion (EDI), present several strategies for promising practices. Hartwell and colleagues cite common learning objectives for promoting EDI: (a) the importance of awareness, (b) knowledge, and (c) skills. Awareness is best cultivated early in one's educational journey. Toward that end, the authors recommend developing specific activities to promote awareness.

TABLE 4.2 In-Class Activities to Promote Cultural Awareness ${ }^{a}$

\begin{tabular}{|c|c|c|}
\hline STRATEGIES & PURPOSE & ACTIVITIES \\
\hline \multirow[t]{2}{*}{ Awareness } & $\begin{array}{l}\text { Cultural Chest Activity } \\
\text { To increase awareness of self and oth- } \\
\text { ers. Hartwell (2017) and colleagues } \\
\text { suggest that students first "develop } \\
\text { an awareness of their own social } \\
\text { and cultural identities, values, and } \\
\text { biases" (p. 145). } \\
\text { Students engage in a process of } \\
\text { self-discovery. This activity is mod- } \\
\text { eled by the instructor but could } \\
\text { also be used by field instructors for } \\
\text { school social work interns. }\end{array}$ & $\begin{array}{l}\text { Cultural Chest Activity } \\
\text { Step 1: Students decorate the outside } \\
\text { of the box or bag with images that } \\
\text { demonstrate how they believe oth- } \\
\text { ers see them. } \\
\text { Step 2: In short presentations (3-5 } \\
\text { minutes), students share their boxes } \\
\text { with the class (displaying how it is } \\
\text { decorated and sharing the contents } \\
\text { of the box). } \\
\text { Step 3: Engage students in a thorough } \\
\text { debriefing exercise to promote self/ } \\
\text { other discovery. }\end{array}$ \\
\hline & $\begin{array}{l}\text { Personal Mission Statement } \\
\text { Hartwell and colleagues assert that } \\
\text { writing a personal mission state- } \\
\text { ment helps students examine } \\
\text { what is most important to them. } \\
\text { It allows them to reflect on their } \\
\text { own strengths and weaknesses as } \\
\text { emerging professionals and clarify } \\
\text { their own values. } \\
\text { The goal is for students to develop a } \\
\text { life plan that aligns with their goals. } \\
\text { For instance, if they choose family } \\
\text { values over higher pay, they may } \\
\text { seek employment with greater clar- } \\
\text { ity to reach their stated goals. }\end{array}$ & $\begin{array}{l}\text { Personal Mission Statement } \\
\text { Step 1: Students should list and "rank } \\
\text { their preferences according to im- } \\
\text { plied goals (ends desired by the } \\
\text { person), norms (acts approved by } \\
\text { the person), and beliefs (ideas ac- } \\
\text { cepted by the person)" (Hartwell } \\
\text { et al., 2017, p. 146). }\end{array}$ \\
\hline
\end{tabular}


TABLE 4.2 In-Class Activities to Promote Cultural Awareness ${ }^{\text {a }}$ (continued)

\begin{tabular}{|c|c|c|}
\hline STRATEGIES & PURPOSE & ACTIVITIES \\
\hline & $\begin{array}{l}\text { Making the Personal Public } \\
\text { The third major strategy relates to } \\
\text { making the personal public. All the } \\
\text { activities and assignments should } \\
\text { include debriefing (in some form) } \\
\text { and it should involve the whole } \\
\text { class. The debriefing process is key } \\
\text { to promoting understanding and } \\
\text { creating connections. The goal is to } \\
\text { deepen students' understanding of } \\
\text { equity, diversity, and inclusion. }\end{array}$ & $\begin{array}{l}\text { Making the Personal Public } \\
\text { Step 1: As students engage in any } \\
\text { of these activities they should be } \\
\text { prompted to keep notes in prepara- } \\
\text { tion for crucial conversations to take } \\
\text { place in the debriefing sessions. } \\
\text { Reflective questions may include: } \\
\text { 1. Why did we do this activity? } \\
\text { 2. What were some common themes } \\
\text { and differences you noticed? } \\
\text { 3. What voices are missing? } \\
\text { 4. How might you use these activities } \\
\text { in your own practice? }\end{array}$ \\
\hline & $\begin{array}{l}\text { A Single Story } \\
\text { Hartwell and colleagues make refer- } \\
\text { ence to a TED Talk we use in class, } \\
\text { titled The Danger of a Single Story } \\
\text { by Chimamanda Ngozi Adichie } \\
\text { (2009). Adichie is a renowned au- } \\
\text { thor and speaker. Her lecture is } \\
\text { among the top ten most-viewed } \\
\text { TED Talks and had more than } 15 \\
\text { million views (as of 2020). }\end{array}$ & $\begin{array}{l}\text { A Single Story } \\
\text { Step 1: View the video in class (18 } \\
\text { minutes) } \\
\text { Step 2: Debrief in class in small groups } \\
\text { Step 3: Use the following prompt to } \\
\text { guide the discussion: } \\
\text { "Share a time that you felt that oth- } \\
\text { ers viewed you through the lens of a } \\
\text { 'single story' and/or a time that you } \\
\text { recognized that you 'single-storied' } \\
\text { another person" (Hartwell et al., } \\
\text { 2017, p. 148). }\end{array}$ \\
\hline Knowledge & $\begin{array}{l}\text { Identity Wheel } \\
\text { Hartwell and colleagues suggest three } \\
\text { essential strategies for increasing } \\
\text { student knowledge: } \\
\text { 1. activate prior knowledge, } \\
\text { 2. connect learning to one's field (of } \\
\text { study/discipline), and } \\
\text { 3. provide tools for continued } \\
\text { learning. }\end{array}$ & $\begin{array}{l}\text { Identity Wheel } \\
\text { Griffin's (2007) Identity Wheel } \\
\text { Step 1: Use the Identity Wheel in class } \\
\text { Step 2: Students identify their so- } \\
\text { cial group identities and statuses } \\
\text { (privileged or nondominant/ } \\
\text { nonprivileged) } \\
\text { Step 3: Engage in classroom discussion } \\
\text { using the following questions as } \\
\text { prompts: } \\
\text { "Which identities do you think } \\
\text { about most often and least often? } \\
\text { Which identities were difficult for } \\
\text { you to identify and why?" (Hartwell } \\
\text { et al., 2017, p. 149). } \\
\text { Step 4: Engage in debriefing with a } \\
\text { focus on how they may use this ac- } \\
\text { tivity with youth in schools. If used } \\
\text { with youth, ground rules and discus- } \\
\text { sion about respecting the privacy of } \\
\text { others is important to maintaining a } \\
\text { safe space for sharing. } \\
\text { This may also be a good tool for } \\
\text { social workers to use when con- } \\
\text { ducting professional development } \\
\text { workshops for teachers and/or } \\
\text { parents. }\end{array}$ \\
\hline
\end{tabular}




\section{TABLE 4.2 In Class Activities to Promote Cultural Awareness ${ }^{\mathrm{a}}$ (continued)}

\begin{tabular}{|c|c|c|}
\hline STRATEGIES & PURPOSE & ACTIVITIES \\
\hline & Common Ground & $\begin{array}{l}\text { Common Ground } \\
\text { Step 1: Students stand in a wide circle } \\
\text { (in silence)/in class } \\
\text { Step 2: Professor calls out a list of } \\
\text { privileges } \\
\text { Step 3: Students are expected to step } \\
\text { inside the circle if the privilege ap- } \\
\text { plies to their life experiences } \\
\text { Step 4: After the activity have students } \\
\text { reflect on it individually (in solitude) } \\
\text { Step 5: Engage in debriefing } \\
\text { Consider the following prompts: } \\
\text { What was it like for you to partici- } \\
\text { pate in this activity? } \\
\text { How might you use this with youth } \\
\text { in schools to increase understanding } \\
\text { and connection? }\end{array}$ \\
\hline \multirow[t]{2}{*}{ Skills } & $\begin{array}{l}\text { Skill Development } \\
\text { Skill development is important for en- } \\
\text { gaging with equity, diversity, and } \\
\text { inclusion. Hartwell and colleagues } \\
\text { define skills as those behaviors } \\
\text { necessary for transacting awareness } \\
\text { and knowledge. }\end{array}$ & $\begin{array}{l}\text { Communication Skills } \\
\text { Communication skills include using lan- } \\
\text { guage effectively and appropriately } \\
\text { while also engaging in active listening. } \\
\text { Keller and Grumbach suggest the fol- } \\
\text { lowing activity to enhance commu- } \\
\text { nication skills: } \\
\text { Step 1: Select a video clip of a counsel- } \\
\text { ing session with a school-age child } \\
\text { or adolescent } \\
\text { Step 2: Encourage students to listen for } \\
\text { what is being said and what is not be- } \\
\text { ing said (listening with the "third ear"). } \\
\text { Step 3: Ask students to consider ways } \\
\text { communication may be improved (if } \\
\text { at all) }\end{array}$ \\
\hline & $\begin{array}{l}\text { Co-create Guidelines for Activities/ } \\
\text { Class }\end{array}$ & $\begin{array}{l}\text { Co-create Guidelines for Activities/Class } \\
\text { Step 1: Ask students to list guidelines } \\
\text { for respectful class discussion } \\
\text { Step 2: Try to reach consensus } \\
\text { Step 3: Post guidelines and adhere to } \\
\text { them }\end{array}$ \\
\hline
\end{tabular}

${ }^{a}$ Hartwell, E. E., Cole, K., Donovan, S. K., Greene, R. L., Storms, S. L. B., \& Williams, T. (2017). Breaking down silos: Teaching for equity, diversity, and inclusion across disciplines. Humboldt Journal of Social Relations, 1(39), 143-162.

See Hartwell and colleagues for other assignments and activities for promoting cultural awareness. They suggest using autobiographies, cultural genograms, community-based learning projects, and other learning activities.

Students are encouraged to know themselves, their cultural background, and ethnic identity before learning about the identity of others. The development of self-knowledge leads to a self-reflexive process of examining one's own biases. Learning about others helps to broaden one's perspective-taking and the development of empathy through understanding. 


\section{PRACTITIONER SPOTLIGHT 4.1}

\section{CREATING CULTURALLY RESPONSIVE PRACTICES IN SCHOOLS}

Ms. Miller is a social worker who works at the district level as the family engagement coordinator. The district is midsized and serves a diverse population (31\% Latinx, 29\% White, 10\% Black, 6\% Pacific Islander, $6 \%$ Asian, $1 \%$ Native American, $17 \%$ multiracial). Nearly $70 \%$ of the student population is designated as low income and $12 \%$ are EL. However, $82 \%$ of classroom teachers are White, similar to the teaching force in the country as a whole. As a member of the leadership team, Ms. Miller has sought to promote two linked initiatives: (a) becoming an antiracist educator and (b) reimagining parent engagement as parent/caregiver leadership. In seeking to develop a school district that is actively antiracist, the district has implemented racial equity training for all staff with an intentional focus on school administrators. The training sessionsfocus on understanding the tenets of White supremacy and how this shows up in everyday practice. Part of this emphasis is in recruiting, hiring, and retaining BIPOC staff. The second initiative, developing a stronger partnership with parents and families, provides an opportunity for Ms. Miller to emphasize a strengths perspective with families, focusing on family protective factors. She notes that families are not always viewed positively or as experts. In a recent effort to shift families into leaders, the district contracted parents as members of the interview panel, compensating them for their time and expertise. Through these efforts, Ms. Miller is helping the district to be more responsive to families and to move toward an active antiracist stance in building administration.

\section{CHAPTER SUMMARY}

In this chapter, the authors addressed key concepts for understanding diversity, inclusion, racial power dynamics, and racial justice related to school social work practice. The authors provided a brief historical review of key legislation (i.e., Brown v. the Board of Education) and the entrenchment of segregation in U. S. policies, including de facto segregation as a form of continual resistance to inclusive services for all students. The chapter focused on the practice routines of school social workers to provoke thoughtful dialogue about ways to contest the status quo. Practice issues related to the strengths perspective provide guidance for addressing social justice and diversity in educational settings. Furthermore, the authors highlight the importance of being a culturally competent and humble professional, especially when working with diverse families.

Finally, the authors hope that after reading this chapter, students will take seriously the need for examining microaggressions and social/educational injustice within the context of school systems (Nakaoka \& Ortiz, 2018), as well as examining and addressing one's own implicit biases.

\section{RESOURCES}

Bias Isn't Just a Police Problem, It's a Preschool Problem | Let's Talk | NPR https://www.youtube.com/watch?v=ucEAcIMkS0c\&feature=youtu.be (2 minutes)

TED Talk: The Danger of a Single Story (The talk addresses the need to recognize power and privilege

- Chimamanda Ngozi Adichie, 2009)

https://www.ted.com/talks/chimamanda_ngozi_adichie_the_danger_of_a_single_story 
TED Talk: The Consciousness Gap in Education (The talk addresses the gap in education related

to racial/ethnic differences - Dorinda Carter Andrews, 2014)

https://www.youtube.com/watch? $\mathrm{v}=\mathrm{iOrgf3}$ wTUbo

The Most Intense Heartfelt Description of Racism I Ever Filmed (interview by David Hoffman) https://www.youtube.com/watch?v=IXUFiXeNZV4Youth.gov

https://youth.gov/youth-topics/lgbtq-youth/school-experiences

\section{REFERENCES}

American Institutes for Research. (2020, October 21). News Release. Challenges educating students with disabilities and English Learners during Covid-19. https://www.air.org/news/press-release/ challenges-educating-students-disabilities-and-english-learners-during-covid-19

Anzaldúa, G. (1987). Borderlands/La frontera: The new mestiza. Spinsters/Aunt Lute Book Company. Barsky,A.(2018).Ethicsalive!Culturalcompetence, awareness, sensitivity, humility, andresponsiveness: What's the difference? The New Social Worker. https://www.socialworker.com/feature-articles/ ethics-articles/ethics-alive-cultural-competence-awareness-sensitivity-humility-responsiveness/

Blair, S. L. (2014). Parental involvement and children's educational performance: A comparison of Filipino and U.S. parents. Journal of Comparative Family Studies, 45(3), 351-366. https://doi .org/10.3138/jcfs.45.3.351

Brown v. Board of Education. (1954). 347 U.S. 483.

Center for Disease Control and Prevention. (2018). Youth risk behavior survey data summary \& trends report 2007-2017. https://www.cdc.gov/healthyyouth/data/yrbs/pdf/trendsreport.pdf

Clark-Gareca, B., Short, D., Lukes, M., \& Sharp-Ross, M. (2020). Long-term English learners: Current research, policy, and practice. TESOL Journal, 11(1), e00452. https://doi.org/10.1002/tesj.452

Children's Bureau. (2021, March). Foster care statistics 2019. US Department of Health and Human Services. https://www.childwelfare.gov/pubPDFs/foster.pdf

Children's Defense Fund. (2021, June). The state of America's children. https://www.childrensdefense .org/state-of-americas-children/soac-2021-child-poverty/

Council on Social Work Education. (2021, April). Educational policy and accreditation standards for baccalaureate and master's social work programs - Draft 1. https://www.cswe.org/getattachment/ Accreditation/Information/2022-EPAS/EPAS-2022-Draft-1-April-2021-(2).pdf.aspx

Feagin, J. R. (2004). Toward an integrated theory of systemic racism in M. Krysan \& A. M. Lewis (Eds), The changing terrain of race and ethnicity (pp. 203-223). Russell Sage Foundation.

Goldbach, J. T., Amaro, H., Vega, W., \& Walter, M. D. (2015). The grand challenge of promoting equality by addressing social stigma (Grand Challenge for Social Work Initiative Working Paper No. 15). American Academy of Social Work and Social Welfare.

Grand Challenges for Social Work. (n.d.). The challenges. https://grandchallengesforsocialwork .org/\#the-challenges

Hartwell, E. E., Cole, K., Donovan, S. K., Greene, R. L., Storms, S. L. B., \& Williams, T. (2017). Breaking down silos: Teaching for equity, diversity, and inclusion across disciplines. Humboldt Journal of Social Relations, 1(39), 143-162. https://digitalcommons.humboldt.edu/cgi/viewcontent .cgi?referer=https://scholar.google.com/\&httpsredir $=1$ \&article $=1009 \&$ context=hjsr

Henderson, A. T., \& Mapp, K. L. (2002). A new wave of evidence. The impact of school, family, and community connections on student achievement. National Center for Family \& Community: Connections with Schools. https://sedl.org/connections/resources/evidence.pdf

Hornby, G. \& Blackwell, I. (2018). Barriers to parental involvement in education: An update, Educational Review, 70(1), 109-119, DOI: 10.1080/00131911.2018.1388612

Jeynes, W. H. (2017). A meta-analysis: The relationship between parental involvement and Latino student outcomes. Education and Urban Society, 49(1), 4-28. https://doi.org/10.1177 /0013124516630596 
Kopels, S., \& Pacely, M. S. (2012). Reducing bullying toward LGBTQ students in schools. School Social Work Journal, 37(1), 96-111. https://www.ingentaconnect.com/content/iassw/sswj/2012 /00000037/00000001/art00008

Kulkarni, S. S. (2020). Racial and ethnic disproportionality in special education programs. Oxford Research Encyclopedia, Education. https://doi.org/10.1093/acrefore/9780190264093.013.1242

Lee, M. Y., Ely, C. G., Eads, R., \& Wang, X. (2020). Collaborative and strengths-based intervening with students from single-parent families. In Encyclopedia of Social Work. https://doi.org/10.1093/ acrefore/9780199975839.013.1234

McCardle, M., \& Bliss, S. (2019). Digging deeper: The relationship between school segregation and unconscious racism. Smith College Studies in Social Work, 89(2) 114-131. https://doi.org/10.1080 /00377317.2019.1686929

McIntosh, P. (1989, July/August). White privilege: Unpacking the invisible knapsack. Peace and Freedom Magazine, 10-12.

Morgan, P. L., Farkas, G., Cook, M., Strassfeld, N. M., Hillemeier, M. M., Pun, W. H., Wang, Y., \& Schussler, D. L. (2018). Are Hispanic, Asian, Native American, or language-minority children overrepresented in special education? Exceptional Children, 84(3), 261-279. https://doi .org/10.1177/0014402917748303

Nakaoka, S., \& Ortiz, L. (2018). Examining racial microaggressions as a tool for transforming social work education: The case for critical race pedagogy. Journal of Ethnic \& Cultural Diversity in Social Work, 27(1), 72-85. https://doi.org/10.1080/15313204.2017.1417947

Parolin, Z., Curran, M., Matsudaira, J., Waldfogel, J., \& Wimer, C. (2020). Monthly poverty rates in the United States during the COVID-19 pandemic. Center on Poverty and Social Policy at Columbia University.

Rodriguez, S., Roth, B., \& Villareal Sosa, L. (2020). School social workers as Nepantleras in equity work for immigrant students: A conceptual exploration. Social Service Review, 94(4), 748-780. https://doi.org/10.1086/712044

Saad, L. F. (2020). Me and white supremacy: Combat racism, change the world, and become a good ancestor. Sourcebooks.

Saleebey, D. (2009). The strengths perspective in social work practice (5th ed.). Pearson.

Smith, W. A., Hung, M., \& Franklin, J. D. (2012). Between hope and racial battle fatigue: African American men and race-related stress. Journal of Black Masculinity, 2(1), 35-58. https://www .researchgate.net/publication/236975384_Between_Hope_and_Racial_Battle_Fatigue_African _American_Men_and_Race-Related_Stress?

Stone, S. (2017). Racial equity and school social work. Psychology in the Schools, 54(10), 1238-1244. https://doi.org/10.1002/pits.22071

Stone, S. \& Uretsky, M. (2016). School correlates of academic behaviors and performance among McKinney-Vento identified youth. Urban Education, 5(16), 600-628. https://doi .org/10.1177/0042085915602540

Sue, D. W. (Ed.). (2010). Microaggressions, marginality, and oppression: Microaggressions and marginality, John Wiley and Sons.

Sue, D.W., Rasheed, M. N., \& Rasheed, J. M. (2015). Multicultural social work practice: A competency-based approach to diversity and social justice. Wiley.

Teasely, M., \& Homer, B. (2020). Racial disparities in the education system. Encyclopedia of Social Work. National Association of Social Workers and Oxford University Press. https://doi.org/10.1093/ acrefore/9780199975839.013.1290

Teasley, M. T., Nevaro, L., \& Frost, C. J. (2017). Bringing attention to issues related to school social work practice with immigrant children and children of undocumented parents. Children \& Schools, 39(4), 195-198. https://doi.org/10.1093/cs/cdx022

TED Global. (2009, July). Chimamanda Ngozi Adichie: The danger of single story [Video file]. https:// www.ted.com/talks/chimamanda_ngozi_adichie_the_danger_of_a_single_story 
Umansky, I. M., Thompson, K. D., \& Díaz, G. (2017). Using an ever-English learner framework to examine disproportionality in special education. Exceptional Children, 84(1), 76-96. https://doi .org/10.1177/0014402917707470

United Nations International Children's Emergency Fund. (2020, April). Child migration. https:// data.unicef.org/topic/child-migration-and-displacement/migration/

United States Department of Education. (2016a, September). Non-regulatory Guidance: English Learners and Title III of the Elementary and Secondary Education Act (ESEA), as amended by the Every Student Succeeds Act (ESSA) https://www2.ed.gov/policy/elsec/leg/essa/ essatitleiiiguidenglishlearners92016.pdf

United States Department of Education. (2016b, July). Supporting the success of homeless children and youths. https://www2.ed.gov/policy/elsec/leg/essa/160315ehcyfactsheet072716.pdf

U.S. Department of Education. (n.d.-a). Students in foster care. https://www2.ed.gov/about/inits/ed/ foster-care/index.html

U.S. Department of Education. (n.d.-b). Overview/Mission. https://www2.ed.gov/about/overview/ mission/mission.html?src=rt

U.S. Department of Education. (n.d.-c). Office of Civil Rights. Ensuring English Learner Students Can Participate Meaningfully and Equally in Educational Programs. https://www2.ed.gov/about/ offices/list/ocr/docs/dcl-factsheet-el-students-201501.pdf

Wilson, S. (2003). Brown over "Other White": Mexican Americans' legal arguments and litigation strategy in school desegregation lawsuits. Law and History Review, 21(1), 145-194. https://doi .org/10.2307/3595071 